\title{
СОВРЕМЕННЫЕ ЦВЕТНЫЕ РЕВОЛЮЦИИ В КОНТЕКСТЕ НАУЧНО-ТЕХНОЛОГИЧЕСКОГО ПОДХОДА
}

\begin{abstract}
Аннотация. Предметом настоящего исследования являются современные знания и представления о природе цветных революций, а также дискуссии, разворачивающиеся вокруг этого явления в российской и зарубежной науке. Автор обращает внимание на то, что в конце XX - начале XXI века в мире появляются новые формы и методы организации государственных переворотов, основанные на применении методов "мягкой силы»так называемые цветные революции. Автор подробно рассматривает цветные революции с позиций двух альтернативных подходов - как явление и как технологию, соглашаясь с мнением тех российских экспертов, которые считают, что современные цветные революции - это технологии государственных переворотов, в которых основным инструментом демонтажа политических режимов инструментом которого выступает молодежное протестное движение, довольно часто идущее на столкновение с властью под националистическими лозунгами. Сигналом для запуска технологий цветных революций становятся выборы-наиболее удобный и ставший уже классическим повод, предполагающей инициирование массовых народных протестов на волне выдвигаемых оппозицией обвинений в якобы имевшей место массовой фальсификации результатов выборов. Это - тот самый классический повод, который был использован в цветной революции в Сербии, в оранжевой революции в Украине, в революции роз в Грузии, и во множестве других стран - привычный и прекрасно отработанный прием, клише, «демократический шаблон». Методологической основой исследования является системный, структурно-функциональный, сравнительно-политический подходы, методы анализа, синтеза, индукции, дедукции, наблюдения. В российском экспертном сообществе сегодня сохраняются две диаметрально противоположные точки зрения относительно природы цветных революций, которые выражаются в конкурентном существовании двух гипотез: френоменологической (рассматривающей цветную революцию как явление) и технологической (рассматривающей цветную революцию как инструмент политического воздействия, как политическую технологию). Целью данного исследования является выявление форм и методов организации и проведения цветных революций в мировой практике.
\end{abstract}

Ключевые слова: политика, общество, США, государство, гибридные войны, цветные революции, демократия, интересы, ценности, безопасность.

Abstract. The subject of this research is the modern knowledge and understanding of the nature of color revolutions, as well as the discussions over this phenomenon in the Russian and foreign science. The author draws attention to the fact that in the late XXth - the early XXIst century the new forms and methods of organizing take-overs, based on the use of methods of "soft power» - the so-called color revolutions, emerge. The author examines in detail a color revolution from the positions of the two alternative approaches - as a phenomenon and as a technology, agreeing with the opinion of the Russian experts, who believe that a modern color revolution is a technology of a take-over and main tool of political regimes dismantle which is based on the youth protest movement clashing with the authority under nationalist slogans. The signal to launch the technologies of color revolutions is the elections - the most convenient and the classic pretext involving the initiation of mass protests on the wave of allegations put forward by the opposition about the massive electoral fraud. This is the most classic pretext that had been used in color revolutions in Serbia, in the Orange Revolution in Ukraine, the Revolution of Roses in Georgia and in many other countries - the habitual and well-tested method, a cliché, a "democratic pattern." The methodological basis of the research is a system, structural and functional, comparative political approaches, the methods of analysis, synthesis, induction, deduction, observation.The Russian expert community today maintains two opposite points of view about the nature of color revolutions, which are expressed in the existence of the two hypotheses: phenomenological (which considers a color revolution as a phenomenon) and technological (which considers a color revolution as an instrument of political influence and as a political technology). The aim of this study is to identify the forms and methods of organizing and conducting color revolutions in the world.

Key words: interests, democracy, color revolutions, hybrid war, state, USA, society, policy, values, security.

$\mathrm{B}$ конце XX начале XXI века появляются новые формы и методы проведения специальных внешнеполитических и военных операций: информационная война [14], кибервойна, цветные революции.
Цветные революции представляют собой новую форму организации государственного переворота в стране, который проводится «ненасильственными методами» под прикрытием «экспорта 
демократии» и социально-экономической справедливости. Фактически, это технологии организации государственного переворота в условиях искуственно созданной политической нестабильности, в которых власть подвергается шантажу со стороны специально организованного и хорошо обученного зарубежными инструкторами молодежного протестного движения [13]. Значительную роль в этом процессе играют инструменты и технологии мягкой силы англосаксонского происхождения, которые есть и у других стран, стремящихся сопротивляться попыткам насильственного захвата власти путем «цветного» переворота [12].

Эти методы стали зарождаться в США после Второй Мировой войны, о чем свидетельствуют документы ЦРУ за 1949 год. В них говорится, что для управления другими государствами необходимо использовать и координировать все средства, главным из которых является моральное и физическое воздействие на населения других стран, исключая военные действия регулярной армии, но используя психологические операции, с помощью которых уничтожается воля врага и подрываются или вообще уничтожаются его политические и экономические возможности [11].

Крупнейшим американским стратегическим исследовательским центром, занимающимся усовершенствованием технологий цветных революций и информационно-психологических операций является Rand Corporation. Здесь необходимо отметить, что данная организация была основана в 1948 году в Санта-Монике (Калифорния) для конструирования самолетов, ракет и спутников. В 1950-х гг. центром выполнялись научно-исследовательские работы по проблемам национальной безопасности, включая военно-технические и стратегические аспекты.

Сегодня Rand Corporation - это огромная транснациональная организация, в работе которой принимают участие свыше 1700 ученых и исследователей из пятидесяти стран мира.

Однако эта организация не является единственной структурой по выработке новых сценариев цветных революций и информационных войн. Проектированием конфликтов занимаются такие научно-исследовательские центры, как Институт Санта-Фе, Дом свободы, Национальный фонд в поддержку демократии, Фонды Форда и Макартуров, Центр СМИ и публичной политики Школы государственного управления им. Кеннеди при Гарвардском университете, Беркмановский центр «Интернет и общество» при Гарвардской школе права, Оксфордский институт Интернета, Школы права Колумбийского и Йельского университетов и др. [5]

Здесь надо отметить, что в научной литературе существует две диаметрально противополож- ные точки зрения о причинах цветных революций. Согласно первой, причинами цветных революций является борьба за сферы влияния на постсоветском пространстве, которую ведут США и ряд европейских государств с Россией, Китаем, странами Латинской Америки. Именно Вашингтон является главным финансовым донором и разработчиком новейших методов проведения государственных переворотов. То есть, цветные революции носят инспирированный характер. В первую группу входят такие ученые, как Манойло А.В.; Пономарева Е.; Александр Ланца; Хайлоу В. и др.

Другая группа исследователей считает, что цветные революции являются реакцией на авторитарное правление в тех странах, где проходят государственные перевороты. Участие США в этих процессах они видят несущественным и направленным на развитие демократических основ в тех странах, которые неспособны сами в силу слаборазвитой политической, экономической и социальной сфер проводить политику в рамках демократических принципов. Во вторую группу входят следующие ученые: Шарп Д.; Craig C. Colucci.; Lincoln A. Mitchell. и др.

На сегодняшний день крупнейшим разработчиком теоретических и практических основ цветных революций является американский общественный деятель Джин Шарп. В своих работах по методам ненасильственный борьбы с авторитарными режимами он утверждает, что ненасильственные действия включают в себя не один десяток специфических форм протеста. Эти протесты, согласно трактовкам автора, проявляются в отказе от сотрудничества и вмешательства, при проведении которых активисты участвуют в конфликте путем осуществления - или отказа от осуществления - определенных действий без использования физического насилия.

Джин Шарп утверждает, что причины, лежащие в основе конфликта, могут быть различны, например, противоборство между политическими группами, действия в поддержку правительства или против него, или, реже, между правительствами (эмбарго или сопротивление оккупации). Кроме того, имеют место и экономические, социальные, религиозные причины. Масштаб и уровень конфликта также варьируются - он может быть ограничен пределами одного района, города, определенной части общества, а в других ситуациях охватывать всю страну. Реже в конфликт вовлекается несколько стран и правительств. Тем не менее, независимо от причин и масштаба конфликта, ненасильственные действия являются методом, с помощью которого люди, отвергающие пассивность и подчинение и считающие необходимым продолжать борьбу, могут участвовать в конфликте без 
использования насилия. Ненасильственные действия не являются попыткой избежать конфликта или игнорировать его [7].

Шарп выделяет следующие методы «ненасильственной борьбы», которые необходимы для удачного государственного переворота:

- публичные выступления;

- письма протеста или поддержки;

- лозунги, карикатуры и символы;

- $\quad$ групповое лобби;

- псевдо-выборы;

- с символические общественные акции;

- $\quad$ поминание умерших и др. [7]

Таким образом, методом революционного процесса является совокупность определенных приемов и специальных операций, которые направленны на изменение политической и социально-экономической активности целевых аудиторий внутри страны с целью нарушения функционирования органов государственной власти и смены правящей элиты.

Первоначальная задача для достижения поставленной цели - постоянная активность внутренних целевых аудиторий. Для их активизации используются следующие методы:

- Мобилизация населения, куда входит психологическая работа с целевой аудиторией, направленная на усиление ее решимости, уверенности и навыкам сопротивления и координация четкого плана общественных организаций, работающих с целевыми аудиториями.

- Перехват власти. Как правило, происходит замена политической власти в стране или блокирование на выборах законных кандидатов. Ярким наглядным примером может служить государственный переворот в Гондурасе в июне 2009 года, когда митингующие взяли под арест президента страны Мануэля Селайю и насильно вывезли его в Коста-Рику, после чего парламент Гондураса принял решение об отставке М. Селайи и назначил временно исполняющим обязанности главы государства председателя парламента Роберто Мичелетти. Здесь необходимо отметить, что за месяц до переворота в стране была создана целая оппозиционная коалиция, которая состояла из различных политических и деловых организаций, куда входили: «Демократический гражданский союз Гондураса», Гондурасский совет частного предпринимательства, Совет деканов университета, Федерация рабочих Гондураса, Национальный форум сближения, Национальная торгово-промышленная федерация Гондураса, Ассоциация средств массовой информации, Группа за мир и демократию и студенческая группа «Поколение за перемены». [1] Эти ор- ганизации являются бенефициарами более чем пятидесяти миллионов долларов, которые ежегодно выделяются Агентством США по международному развитию, и Национальным фондом за демократию для «продвижения демократии» в Гондурасе.

- Формирование негативного образа легитимной власти и ее лидера. В отношении легитимного правительства снимаются социокультурные и барьерные нормы, что является психологической основой внутренней легитимности любого политического режима.

- Создание позитивного имиджа нового кандидата. Как правило, нелегитимный лидер формирует свой имидж через СМИ и социальные сети, принимая постановочное участие в акциях протеста. Ярким примером здесь может служить действия украинских оппозиционных политиков во время майдана.

- Нарушение работы государственных институтов и СМИ. Используется оппозиционными силами под прикрытием борьбы за демократию. Во время политического кризиса в стране, органы государственной власти решают вопросы жизнеобеспечения страны и принимают экстренные решения. Сбой работы государственных органов может оказать серьезное воздействие на общество и придать дополнительный стимул протестующим.

- Создание атрибутики. Важным моментом в проведении цветных революций является создание внешней атрибутики (лозунги и символы), как это было в Сербии - сжатый кулак, на Украине - оранжевый цвет, в Грузии - Роза, в Киргизии - Тюльпан.

- Манипуляция целевыми аудиториями в социальных сетях. Проведение информационно-психологических операций путем использования новейших каналов коммуникации, направленных на запугивание населения, появление вражды к действующему режиму и призыву к претесным действиям. Этот метод направлен в первую очередь на оказание влияния на молодежные целевые аудитории, которые являются основным анклавом цветных революций.

- Непризнание итогов голосования. Протестные выступления в связи с недовольством результатами выборов носят спланированный характер, причем акцент делается на «мирном» противостоянии с властью. Однако, без сомнения, заранее скрытно готовятся группы силового давления и противодействия [3].

Анализируя эволюцию методов проведения подобного рода государственных переворотов, необходимо отметить тот факт, что в Восточной 
Европе смена коммунистических режимов, происходившая в результате так называемых бархатных революций, представляла собой изменение общественной формации, но уже на следующем этапе реализации своей политики США и их европейские партнеры стали прибегать к подготовке и реализации переворотов, в результате которых к власти приходили политические лидеры, полностью опиравшиеся на финансовую и политическую поддержку стран запада.

В результате «цветные революции», которые происходили в период с 2003 по 2015 гг. в Грузии, на Украине, в Киргизии, в Гондурасе и на Ближнем Востоке, объединены множеством схожих признаков и по своему характеру напоминают бархатные революции в отдельных странах Восточной Европы в $\mathrm{XX}$ веке. Однако подобные перевороты стали новой формой борьбы за власть в бывших республиках Coветского Союза между различными политическими силами и экономическими группировками. [2]
В качестве вывода хотелось бы отметить, что проведение цветных революций в странах постсоветского пространства, на Ближнем Востоке и в Латинской Америке осуществлялось при помощи схожих форм и методов, направленных на дискредитацию легитимной власти и осуществление государственных переворотов. Оппозиционные силы, как правило, финансируются американскими неправительственными организациями, которые оказывают помощь в проведении всей операции.

B XXI веке технологии проведения цветных революций изучаются и разрабатываются ведущими научно-исследовательскими центрами, среди которых ведущее положение занимает транснациональная организация Rand Corporation. Основной идеей, выдвигаемой странами Запада при проведении цветных революций, является экспорт так называемых демократий в страны, которые пытаются проводить независимой внешнеполитический курс и отстаивают идеи многополярного мира.

\section{Библиография:}

1. Голинжер Е. Переворот в Гондурасе - Вашингтонский след. URL: http://www.telesurtv.net/noticias/entrevreportajes/index.php?ckl=326

2. Громова А.В. Роль и место масс-медиа в подготовке и проведении «цветных революций». Автореф. дисс. на соискание ученой степени к.ф.н., М, 2009.

3. Иррегулярные конфликты: цветные революции. Анализ и оценка форм, приемов и способов ведения операций по смене режимов в суверенных государствах. - М, Центр стратегических оценок и прогнозов, 2015.

4. Манойло А.В. Цветные революции и технологии демонтажа политических режимов. http://e-notabene.ru/wi/ article_12614.html

5. Пономарева Е. Рудов Г. «Цветные революции»: природа, символы, технологии. // ОБОЗРEBATEЛЬ-OBSERVER, № 3,2012 .

6. Хайлоу В. Почему США любят «цветные революции» http://inosmi.ru/fareast/20141014/223643988.html

7. Шарп Джин. От диктатуры к демократии: Стратегия и тактика освобождения / Пер. с англ. Н. Козловской.-М.: Новое издательство, 2005.

8. Latsa Alexandre. Les révolutions de couleur en Eurasie. http://www.eurasia-rivista.org/les-revolutions-de-couleur-eneurasie/8546/

9. Lincoln A. Mitchell. The Color Revolutions. Philadelphia: University of Pennsylvania Press, 2012.

10. Maj Craig C. Colucci. Shaping Colombia's Stability through Strategic Communication: Evaluating U.S. Effectiveness / United States Army School of Advanced Military Studies; United States Army Command and General Staff College Fort Leavenworth, Kansas AY, 2009.

11. War Report of the Office of Strategic Service. W., 1949.

12. Будаев А.В. Сравнительный анализ «мягкой силы» во внешней политике России и Бразилии. // Латинская Америка. 2014. № 4. С. 24-31

13. Манойло А.В. Вооруженный мятеж в Украине: волна цветных революций идет на Россию // NB: Международные отношения. - 2014.-№ 3.-C.27-35. DOI: 10.7256/2306-4226.2014.3.11498. URL: http://e-notabene.ru/wi/ article_11498.html

14. Manoilo A.V. World Models and Technologies of Psychological Impact to Resolve International Conflicts. / 8th IEEE International Symposium on Dependable, Autonomic and Secure Computing, DASC 2009 sponsors: IEEE Computer Society Technical Committee on Scalable Computing, National Natural Science Foundation.-2009.-University of Electronic Science and Technology of China, IEEE Chengdu Section Chengdu. pp. 611-614

15. Codagnone C., Filippov V. Equity, exit end national identity in a multinational federation: the "multi-cultural constitutional patriotism" project in Russia. // Journal of ethnic and migration studies. 2000. V. 26. № 2.. P. 263-288.

16. О.Г. Карпович Особенности позиций российских и американских экспертов по вопросам демократизации Ближнего Востока // Политика и Общество. - 2013. - 5. - С. 563 - 567. DOI: 10.7256/1812-8696.2013.05.4.

17. Карпович О.Г. Риски и угрозы цветной революции в России // Политика и Общество. - 2015. - 1. - C. 107 - 115. DOI: 10.7256/1812-8696.2015.1.14141.

18. Манойло А.В. Цветные революции и демонтаж политических режимов // Мировая политика. - 2015. - 2. - С. 1 44. DOI: 10.7256/2409-8671.2015.2.15311. URL: http://www.e-notabene.ru/wi/article_15311.html

19. Карпович О.Г. «Революция зонтиков» в Гонконге: признаки цветной революции // Политика и Общество. 2015. - 4. - C. 543 - 548. DOI: 10.7256/1812-8696.2015.4.13571. 
20. Филимонов Г.Ю., Юраков М. Украинский кризис в зеркале американской внешнеполитической стратегии // Политика и Общество. - 2015. - 2. - C. 221 - 229. DOI: 10.7256/1812-8696.2015.2.13914.

21. Насонкин В.В. Теоретико-методологические подходы к изучению системы образования в современном обществе. // Политика и Общество. - 2013. - 10. - C. 1213 - 1220. DOI: 10.7256/1812-8696.2013.10.10166.

22. Бородин Е.А. Концептуальные основы разумного подхода к мировой политике и роль разума в мировом политическом процессе // Тренды и управление. - 2014. - 1. - C. 3 - 13. DOI: 10.7256/2307-9118.2014.1.12385.

\section{References (transliterated):}

1. Golinzher E. Perevorot v Gondurase - Vashingtonskii sled. URL: http://www.telesurtv.net/noticias/entrev-reportajes/ index.php?ckl=326

2. Gromova A.V. Rol' i mesto mass-media v podgotovke i provedenii «tsvetnykh revolyutsii». Avtoref. diss. na soiskanie uchenoi stepeni k.f.n., M, 2009.

3. Irregulyarnye konflikty: tsvetnye revolyutsii. Analiz i otsenka form, priemov i sposobov vedeniya operatsii po smene rezhimov v suverennykh gosudarstvakh. - M, Tsentr strategicheskikh otsenok i prognozov, 2015.

4. Manoilo A.V. Tsvetnye revolyutsii i tekhnologii demontazha politicheskikh rezhimov. http://e-notabene.ru/wi/ article_12614.html

5. Ponomareva E. Rudov G. «Tsvetnye revolyutsii»: priroda, simvoly, tekhnologii. // OBOZREVATEL”-OBSERVER, № 3, 2012.

6. Khailou V. Pochemu SShA lyubyat «tsvetnye revolyutsii» http://inosmi.ru/fareast/20141014/223643988.html

7. Sharp Dzhin. Ot diktatury k demokratii: Strategiya i taktika osvobozhdeniya / Per. s angl. N. Kozlovskoi.-M.: Novoe izdatel'stvo, 2005.

8. Latsa Alexandre. Les révolutions de couleur en Eurasie. http://www.eurasia-rivista.org/les-revolutions-de-couleur-eneurasie/8546/

9. Lincoln A. Mitchell. The Color Revolutions. Philadelphia: University of Pennsylvania Press, 2012.

10. Maj Craig C. Colucci. Shaping Colombia's Stability through Strategic Communication: Evaluating U.S. Effectiveness / United States Army School of Advanced Military Studies; United States Army Command and General Staff College Fort Leavenworth, Kansas AY, 2009.

11. War Report of the Office of Strategic Service. W., 1949.

12. Budaev A.V. Sravnitel’nyi analiz «myagkoi sily» vo vneshnei politike Rossii i Brazilii. // Latinskaya Amerika. 2014 . № 4. S. 24-31

13. Manoilo A.V. Vooruzhennyi myatezh v Ukraine: volna tsvetnykh revolyutsii idet na Rossiyu // NB: Mezhdunarodnye otnosheniya. - 2014.-№ 3.-S.27-35. DOI: 10.7256/2306-4226.2014.3.11498. URL: http://e-notabene.ru/wi/ article_11498.html

14. Manoilo A.V. World Models and Technologies of Psychological Impact to Resolve International Conflicts. / 8th IEEE International Symposium on Dependable, Autonomic and Secure Computing, DASC 2009 sponsors: IEEE Computer Society Technical Committee on Scalable Computing, National Natural Science Foundation.-2009.-University of Electronic Science and Technology of China, IEEE Chengdu Section Chengdu. pp. 611-614

15. Codagnone S., Filippov V. Equity, exit end national identity in a multinational federation: the "multi-cultural constitutional patriotism" project in Russia. // Journal of ethnic and migration studies. 2000. V. 26. № 2.. P. 263-288.

16. O.G. Karpovich Osobennosti pozitsii rossiiskikh i amerikanskikh ekspertov po voprosam demokratizatsii Blizhnego Vostoka // Politika i Obshchestvo. - 2013. - 5. - S. 563 - 567. DOI: 10.7256/1812-8696.2013.05.4.

17. Karpovich 0.G. Riski i ugrozy tsvetnoi revolyutsii v Rossii // Politika i Obshchestvo. - 2015. - 1. - S. 107 - 115. DOI: 10.7256/1812-8696.2015.1.14141.

18. Manoilo A.V. Tsvetnye revolyutsii i demontazh politicheskikh rezhimov // Mirovaya politika. - 2015. - 2. - S. 1 - 44 . DOI: 10.7256/2409-8671.2015.2.15311. URL: http://www.e-notabene.ru/wi/article_15311.html

19. Karpovich O.G. «Revolyutsiya zontikov» v Gonkonge: priznaki tsvetnoi revolyutsii // Politika i Obshchestvo. - 2015. - 4. S. 543 - 548. DOI: 10.7256/1812-8696.2015.4.13571.

20. Filimonov G.Yu., Yurakov M. Ukrainskii krizis v zerkale amerikanskoi vneshnepoliticheskoi strategii // Politika i Obshchestvo. - 2015. - 2. - S. 221 - 229. DOI: 10.7256/1812-8696.2015.2.13914.

21. Nasonkin V.V. Teoretiko-metodologicheskie podkhody k izucheniyu sistemy obrazovaniya v sovremennom obshchestve. // Politika i Obshchestvo. - 2013. - 10. - S. 1213 - 1220. DOI: 10.7256/1812-8696.2013.10.10166.

22. Borodin E.A. Kontseptual'nye osnovy razumnogo podkhoda k mirovoi politike i rol' razuma v mirovom politicheskom protsesse // Trendy i upravlenie. - 2014. - 1. - S. 3 - 13. DOI: 10.7256/2307-9118.2014.1.12385. 